\title{
PAX-5: A Valuable Immunohistochemical Marker in the Differential Diagnosis of Lymphoid Neoplasms
}

Mohamed M. Desouki, MD, PhD; Ginell R. Post, MD, PhD; Daniel Cherry, MD; and John Lazarchick, MD

\begin{abstract}
Objective: Undifferentiated tumors and hematolymphoid neoplasms can be diagnostically challenging due to potential overlap of morphologic features and variant antigen expression. PAX-5, a transcription factor expressed throughout B-cell maturation, is detected in most B-cell neoplasms including those that lack expression of mature B-cell markers, such as classical Hodgkin lymphoma (cHL), B-lymphoblastic leukemia and B-cell lymphomas following rituximab therapy. The lack of PAX-5 expression in most CD30-positive non-hematopoietic malignancies (embryonal carcinoma and seminoma) and T-cell lymphomas, such as anaplastic large cell lymphoma (ALCL), suggests that the absence of PAX-5 may be used to confirm non-B-cell lineage. The goal of this study was to retrospectively assess PAX-5 immunoreactivity in diagnostic samples of hematolymphoid and other non-hematopoietic malignancies.
\end{abstract}

Design: Diagnostic lymph node, decalcified core bone marrow biopsies and tissue sections from III archived paraffin-embedded tissue blocks and a tissue lymphoma microarray were immunostained using a monoclonal antibody to PAX-5. The corresponding hematoxylin and eosin stained tissue sections and additional immunostains were simultaneously evaluated. PAX-5 immunoreactivity in neoplastic cells was scored as positive or negative. This study was exempted by the Institutional Review Board for Human Research.

Results: Nuclear PAX-5 immunoreactivity was detected in $88 \%$ (36/4I) of Hodgkin lymphoma, all cases of diffuse large B-cell lymphoma $(n=72)$, small B-cell lymphomas $(n=5)$, B-lymphoblastic leukemia/ lymphoma and mixed phenotype acute leukemia with B-cell lineage $(n=5)$. PAX-5 was not detected in ALCL ( $n=22)$, T-cell lymphoblastic leukemia/lymphoma, mixed phenotype acute leukemia with T-cell lineage $(n=5)$, acute myeloid leukemia $(n=4)$, carcinoid tumors with typical morphology $(n=5)$, melanoma $(n=3)$, and undifferentiated/metastatic tumors $(n=8)$. Non-neoplastic bone marrow sections showed scattered nuclear staining in small B-cell lymphocytes/hematogones. The detection of PAX-5 immunoreactivity resulted in the reclassification of two cases of ALCL to CHL.

Conclusion: Overall, our results demonstrate that including PAX-5 in a panel with other immunomarkers helps establish B-cell lineage and increases diagnostic yield.

Keywords: Anaplastic large cell lymphoma; Diffuse large B-cell lymphoma; Hodgkin lymphoma; PAX-5; Undifferentiated tumors

Corresponding Author: John Lazarchick, MD; Department of Pathology \& Laboratory Medicine; Medical University of South Carolina; Charleston, SC 29425; Tel: 843-792-0217; Email: lazarj@musc.edu
Received: October I, 2009

Ist Revision: January II, 2010

2nd Revision: March 18, 2010

Accepted: March 24, 2010

doi: $10.3121 / \mathrm{cmr} .2010 .891$ 
ndifferentiated, anaplastic, and certain hematolymphoid malignancies can constitute a diagnostic challenge due to overlap of morphologic features and antigen expression. In most cases, immunohistochemical characterization using a panel of antibodies can resolve cell lineage, providing valuable diagnostic information, and would typically include antibodies to CD45 (hematolymphoid), cytokeratin (carcinoma), vimentin (sarcoma), and synaptophysin (neuroendocrine). The initial immunohistochemical panel for lymphomas would include CD20 (B-cells), CD3 (T-cells), CD138 (plasma cells) and CD30 (Reed-Sternberg cells of classical Hodgkin lymphoma (cHL), anaplastic B- and T-cell lymphomas.) Multiple antibodies are then utilized for subtyping the B- and T-cell lymphomas to make a specific diagnosis. However, cHL, a tumor of B-cell lineage that is CD45 negative, often lacks expression of pan B-cell markers (CD20 and CD79a) and/or may paradoxically express T-cell antigens. Absence of CD20 and expression of CD30 can make cHL particularly difficult to distinguish from anaplastic large cell lymphoma (ALCL), a T-cell malignancy. The latter may lack the expression of many T-cell antigens. ${ }^{1}$ Similarly, rituximab therapy in patients with B-cell lymphomas is associated with loss of CD20 immunoreactivity, ${ }^{2-4}$ making the use of CD20 immunohistochemistry unreliable for detection of residual disease.

The B-cell-specific activator protein, PAX-5, is a nuclear transcription factor which plays a major role in B-cell differentiation and proliferation. 5,6 PAX-5 gene expression is increased during early B-cell development and retained throughout maturation, but is absent in plasma cells ${ }^{7-9}$ and T-cells. ${ }^{10}$ PAX-5 is expressed in the vast majority of B-cell malignancies. ${ }^{10,11}$ In addition, PAX-5 immunoreactivity is detected in subsets of epithelial and mesenchymal tumors, including poorly differentiated neuroendocrine carcinoma, mesonephric carcinoma, cervical carcinoma, ${ }^{12}$ Merkel cell carcinoma, small cell carcinomas, aggressive neuroblastoma, ${ }^{10,12-15}$ squamous cell carcinoma of the oral cavity, ${ }^{16}$ Wilms tumors, and alveolar rhabdomyosarcoma. ${ }^{17}$

The primary aim of this study was to establish the utility of including PAX-5 in a panel of antibodies to distinguish CD30-positive lymphoproliferative disorders with an emphasis on cHL and ALCL. A smaller number of other B- and T-cell hematopoietic neoplasms and non-hematopoietic malignancies were included as a secondary goal. We found that PAX-5 immunoreactivity lead to revision of the diagnosis to $\mathrm{cHL}$ in two cases that were originally diagnosed as ALCL.

\section{Methods}

Cases and tissue microarray

A total of 111 cases of undifferentiated, anaplastic, and hematolymphoid malignancies from archived paraffinembedded formalin-fixed tissue blocks from the Department of Pathology at the Medical University of South Carolina and

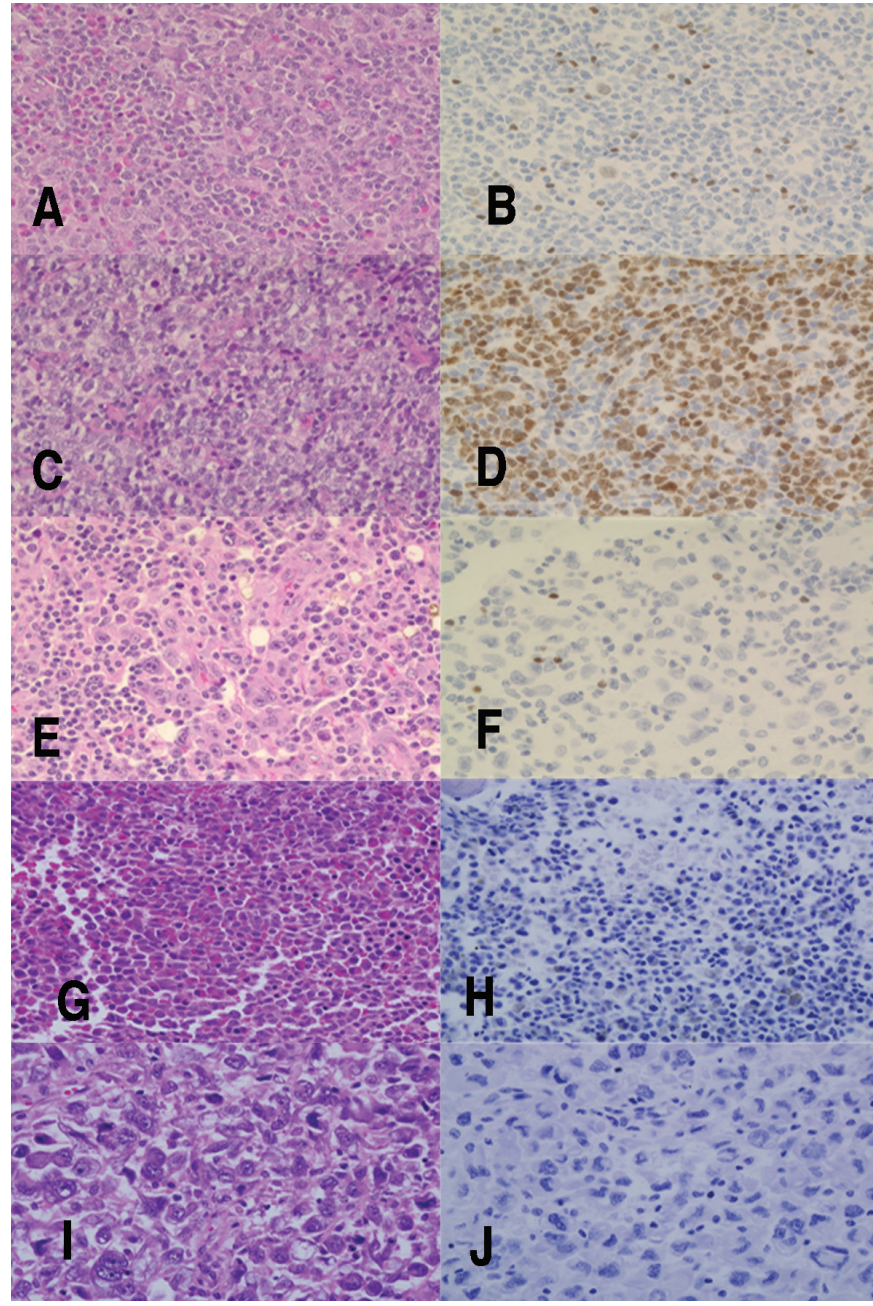

Figure 1: Left side panels (hematoxylin and eosin stain) and right side panels (PAX-5 immunohistochemical stain) of representative fields for (A and $B$ ) classical Hodgkin lymphoma; ( $C$ and $D$ ) diffuse large B-cell lymphoma (DLBCL); ( $E$ and $F$ ) anaplastic large cell lymphoma (ALCL); (G and $H$ ) acute myeloid leukemia (AML); and (I and $J$ ) undifferentiated carcinoma. Note strong nuclear PAX-5 immunostaining in DLBCL (D) in contrast to faint staining in Reed-Sternberg Hodgkin lymphoma cells (B). ALCL (F), AML (H) and undifferentiated carcinoma (J) cases are totally negative for PAX-5 staining (original magnification $\times 400$ ).

Trident Medical Center, (Charleston, SC) from the period of 1997 to 2008, and a 69 sample tissue microarray (Imgenex, San Diego, CA) were examined for PAX-5 expression.

The cases included cHL with differential expression of CD30 and CD15 $(n=41)$, diffuse large B-cell lymphoma $(n=72)$, small B-cell lymphoma ( $\mathrm{n}=5)$, B-cell lymphoblastic leukemia/ lymphoma (LBL) and mixed phenotype acute leukemias with B-cell lineage $(n=5)$, ALCL with differential expression of CD30, ALK-1, and CD3 ( $\mathrm{n}=22$ ), and T-cell LBL and mixed phenotype acute leukemias with T-cell lineage $(\mathrm{n}=5)$. PAX-5 expression was also evaluated in acute myeloid leukemia (AML) $(n=4)$, carcinoid tumors $(n=5)$, melanomas $(n=3)$, 
Table 1: Morphology and immunophenotype of Hodgkin lymphoma $(n=41)$.

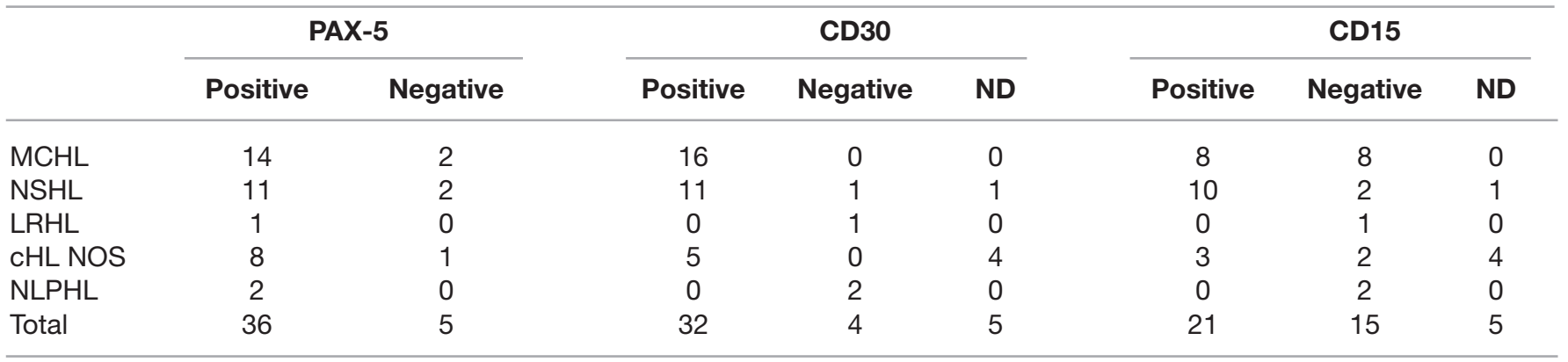

MCHL: Mixed cellularity Hodgkin lymphoma; NSHL: Nodular sclerosis Hodgkin lymphoma; LRHL: Lymphocyte-rich classic Hodgkin lymphoma; cHL NOS: classic Hodgkin lymphoma not otherwise specified; NLPHL: Nodular lymphocyte-predominant Hodgkin lymphoma; ND: Not determined

undifferentiated/metastatic tumors $(\mathrm{n}=8)$, and benign bone marrow $(\mathrm{n}=10)$. The corresponding hematoxylin and eosin stained tissue sections $(\mathrm{n}=111)$ and available immunostains were re-evaluated for diagnostic confirmation.

\section{Immunohistochemistry}

Tissue sections from decalcified bone marrow core biopsies, lymph nodes, and other soft tissue sections were processed for immunohistochemistry using a Dako autostainer (Dako Cytomation, Carpinteria, CA). The immunostain panel used in the study included antibodies to PAX-5, CD45, CD20, CD3, CD30, CD15 and ALK-1. Because some antibodies do not work well in decalcified specimens, we optimized the antigen retrieval and staining protocol for PAX-5. We utilized positive and negative control cases from decalcified bone marrow biopsies and non-decalcified sections and found no differences in PAX-5 nuclear immunoreactivity. Briefly, slides were deparaffinized with heating and xylene incubation. Antigen retrieval was performed using high $\mathrm{pH}$ EDTA at $99.3^{\circ} \mathrm{C}$ for 20 minutes followed by incubation in $3 \%$ hydrogen peroxide for 10 minutes. Sections were then incubated with monoclonal anti-PAX-5 antibody at 1:100 dilution (Biocare Medical, Concord, CA) at room temperature for 30 minutes, followed by anti-mouse (Envision+ kit, Dako, Carpinteria, CA) for 30 minutes. Color was developed with Dako DAB+ chromogenic substrate system for 10 minutes, followed by Dako DAB enhancer for 5 minutes. Hematoxylin was used as counterstain. The appearance of nuclear immunoreactivity for PAX-5 was scored as positive or negative.

\section{Results}

There were 36 of 41 (88\%) Hodgkin lymphoma cases positive for PAX-5 staining (figure 1A and 1B). The five cases that were negative for PAX-5 were distributed among the morphologic subtypes of Hodgkin lymphoma. There was no difference in PAX-5 immunoreactivity among the tissue sources (core biopsy vs soft tissue sections). Two cases initially diagnosed as ALCL showed PAX-5 immunoreactivity and were subsequently reclassified as cHL NOS (not otherwise specified) (table 1). The immunophenotype of these two cases was as follows: positive for CD30 and negative for CD15, CD20, CD3, ALK-1 and epithelial membrane antigen. The nodular lymphocyte predominance Hodgkin's cases $(\mathrm{n}=4)$ were also PAX-5 positive (table 1).

All cases of diffuse large B-cell lymphoma (72/72) (figure 1C and 1D), including the 57 cases from tissue microarray, small B-cell lymphomas (5/5), and B-cell LBL and mixed phenotype acute leukemia with B-cell lineage $(5 / 5)$ were positive for PAX-5 expression.

PAX-5 was not detected in any of the cases of ALCL ( $\mathrm{n}=22$ ) (table 2) (figure 1E and 1F), T-cell LBL, or mixed phenotype acute leukemia with T-cell lineage $(\mathrm{n}=5)$. Three cases of ALCL that were negative for PAX-5 were also ALK-1 negative by immunohistochemistry. One case was negative for a translocation involving 2 p23.

PAX-5 immunoreactivity was found in scattered B-cells in a patient with AML but was negative in blasts (figure $1 \mathrm{G}$ and $1 \mathrm{H})$. Carcinoid tumors $(\mathrm{n}=5)$, melanomas $(\mathrm{n}=3)$, and undifferentiated $/$ metastatic tumors $(n=8)$ were all negative for PAX-5 (table 3) (figure 1I and 1J). Non-neoplastic bone marrow sections $(\mathrm{n}=10)$ showed scattered positive nuclear staining in small B-lymphocytes/hematogones.

\section{Discussion}

PAX-5 is a transcription factor expressed throughout B-cell development. ${ }^{5-8}$ PAX-5 expression is not detected in plasma cells $^{7-9}$ or T-cells. ${ }^{10}$ The results of this study showed that all

Table 2: Immunophenotype of anaplastic large cell lymphoma $(n=22)$.

\begin{tabular}{lcccccc}
\hline & PAX-5 & CD30 & ALK-1 & CD20 & CD3 & CD45 \\
\hline Positive & 0 & 13 & 4 & 0 & 4 & 4 \\
Negative & 22 & 1 & 3 & 11 & 7 & 2 \\
Not done & 0 & 8 & 15 & 11 & 11 & 16 \\
\hline
\end{tabular}

86 Use of PAX-5 in the diagnosis of lymphoid neoplasms

$C M \& R \quad 2010: 2$ (July) 
Table 3: PAX-5 immunophenotype in acute myeloid leukemia, normal bone marrow and non-lymphoid neoplasms.

\begin{tabular}{lccc}
\hline Diagnosis & Positive & Negative & Total \\
\hline Acute myeloid leukemia & 0 & 4 & 4 \\
Carcinoid tumor & 0 & 5 & 5 \\
Malignant melanoma & 0 & 3 & 3 \\
Metastatic/undifferentiated tumors & 0 & 8 & 8 \\
Normal bone marrow & 3 & 7 & 10 \\
Total & 3 & 27 & 30 \\
\hline
\end{tabular}

previously diagnosed B-cell lymphomas and leukemias showed diffuse and strong nuclear PAX-5 expression in tissue sections and decalcified bone marrow biopsies. These results confirm the ability of PAX-5 nuclear reactivity to mark tumors of mature B-cell lineage ${ }^{9-11,18-21}$ and extend these findings by demonstrating PAX-5 expression in B-cell LBLs and mixed phenotype acute leukemias with B-cell lineage.

In contrast to the B-cell malignancies, none of the T-cell or myeloid malignancies tested were positive for PAX-5. The absence of PAX-5 expression in all cases of T-cell LBL and ALCL confirmed T-cell lineage and diagnosis in these cases. Of note, three of the ALCL cases were also negative for ALK-1 expression by immunohistochemistry and molecular studies (one of three cases tested). PAX-5 expression has been reported in AML with $\mathrm{t}(8 ; 21)^{22-24}$ and a subset of acute promyelocytic leukemia. ${ }^{18,25}$ In agreement, our cases of AML, which were negative for these translocations, were also negative for PAX-5. Thus, the addition of PAX-5 to a panel of immunostains can help rule out T-cell lineage in leukemia, ALK-1-negative ALCL, and a subset of AML with recurring cytogenetic abnormalities.

Similar to other reports, we found faint PAX-5 nuclear staining in the Hodgkin's and Reed-Sternberg cells in the majority of $\mathrm{cHL}$ cases (88\%) irrespective of morphologic subtype. ${ }^{10,11,26}$ An important finding of this retrospective study was that the presence of PAX-5 immunoreactivity led to the reclassification of two cases originally diagnosed as ALCL to cHL NOS. The immunophenotype of these lymph node cases showed immunoreactivity for CD30 but not other markers (CD15, CD20, CD3, ALK-1 and epithelial membrane antigen) (table 1). The correct classification of these malignancies is important, as the therapy and prognosis for cHL and ALCL differs. ${ }^{27}$

All non-hematolymphoid neoplasms examined were negative for PAX-5 immunoreactivity (table 3 ). Torlakovic et al ${ }^{12}$ reported weak positivity PAX-5 in two atypical carcinoid tumors, while others have reported persistent PAX-5 negativity in all typical carcinoid cases. ${ }^{10,15}$ In agreement, the carcinoid cases in our small series were negative for PAX-5 and showed typical morphology. Similar to our findings, Jensen et al ${ }^{11}$ reported negative PAX-5 expression in melanomas and different epithelial adenocarcinomas and squamous cell carcinomas.

\section{Conclusion}

Our results highlight the beneficial role of including PAX-5 in an immunohistochemical panel to diagnose lymphoid neoplasms of B-cell origin. Furthermore, absence of PAX-5 expression is helpful to establish T-cell lineage and rule out non-lymphoid tumors with anaplastic cell morphology (undifferentiated and metastatic tumors).

\section{References}

1. Tzankov A, Bourgau C, Kaiser A, Zimpfer A, Maurer R, Pileri SA, Went P, Dirnhofer S. Rare expression of T-cell markers in classical Hodgkin's lymphoma. Mod Pathol 2005;18: 1542-1549.

2. Foran JM, Norton AJ, Micallef IN, Taussig DC, Amess JA, Rohatiner AZ, Lister TA. Loss of CD20 expression following treatment with rituximab (chimaeric monoclonal anti-CD20): a retrospective cohort analysis. Br J Haematol 2001;114: 881-883.

3. Chu PG, Chen YY, Molina A, Arber DA, Weiss LM. Recurrent B-cell neoplasms after Rituximab therapy: an immunophenotypic and genotypic study. Leuk Lymphoma 2002;43:2335-2341.

4. Davis TA, Czerwinski DK, Levy R. Therapy of B-cell lymphoma with anti-CD20 antibodies can result in the loss of CD20 antigen expression. Clin Cancer Res 1999;5:611-615.

5. Palmisano WA, Crume KP, Grimes MJ, Winters SA, Toyota M, Esteller M, Joste N, Baylin SB, Belinsky SA. Aberrant promoter methylation of the transcription factor genes PAX-5 alpha and beta in human cancers. Cancer Res 2003;63: 4620-4625.

6. Walther C, Guenet JL, Simon D, Deutsch U, Jostes B, Goulding MD, Plachov D, Balling R, Gruss P. Pax: a murine multigene family of paired box-containing genes. Genomics 1991;11:424-434.

7. Horcher M, Souabni A, Busslinger M. PAX-5/BSAP maintains the identity of B cells in late B lymphopoiesis. Immunity 2001;14:779-790.

8. Adams B, Dorfler P, Aguzzi A, Kozmik Z, Urbánek P, MaurerFogy I, Busslinger M. Pax-5 encodes the transcription factor BSAP and is expressed in B lymphocytes, the developing CNS, and adult testis. Genes Dev 1992;6:1589-1607.

9. Krenacs L, Himmelmann AW, Quintanilla-Martinez L, Fest T, Riva A, Wellmann A, Bagdi E, Kehrl JH, Jaffe ES, Raffeld M. Transcription factor B-cell-specific activator protein (BSAP) is differentially expressed in B cells and in subsets of B-cell lymphomas. Blood 1998;92:1308-1316.

10. Mhawech-Fauceglia P, Saxena R, Zhang S, Terracciano L, Sauter G, Chadhuri A, Herrmann FR, Penetrante R. Pax-5 immunoexpression in various types of benign and malignant tumours: a high-throughput tissue microarray analysis. J Clin Pathol 2007;60:709-714. 
11. Jensen KC, Higgins JP, Montgomery K, Kaygusuz G, van de Rijn M, Natkunam Y. The utility of PAX5 immunohistochemistry in the diagnosis of undifferentiated malignant neoplasms. Mod Pathol 2007;20:871-877.

12. Torlakovic E, Slipicevic A, Robinson C, DeCoteau JF, Alfsen GC, Vyberg M, Chibbar R, Flørenes VA. Pax-5 expression in nonhematopoietic tissues. Am J Clin Pathol 2006;126: 798-804.

13. Baumann Kubetzko FB, Di Paolo C, Maag C, Meier R, Schäfer BW, Betts DR, Stahel RA, Himmelmann A. The PAX-5 oncogene is expressed in $\mathrm{N}$-type neuroblastoma cells and increases tumorigenicity of a S-type cell line. Carcinogenesis 2004;25:1839-1846.

14. Kanteti R, Nallasura V, Loganathan S, Tretiakova M, Kroll T, Krishnaswamy S, Faoro L, Cagle P, Husain AN, Vokes EE, Lang D, Salgia R. PAX-5 is expressed in small-cell lung cancer and positively regulates c-Met transcription. Lab Invest 2009;89:301-314.

15. Dong HY, Liu W, Cohen P, Mahle CE, Zhang W. B-cell specific activation protein encoded by the PAX-5 gene is commonly expressed in merkel cell carcinoma and small cell carcinomas. Am J Surg Pathol 2005;29:687-692.

16. Norhany S, Kouzu Y, Uzawa K, Hayama M, Higo M, Koike H, Kasamatu A, Tanzawa H. Overexpression of PAX-5 in oral carcinogenesis. Oncol Rep 2006;16:1003-1008.

17. Sullivan LM, Atkins KA, Legallo RD. PAX immunoreactivity identifies alveolar rhabdomyosarcoma. Am J Surg Pathol 2009;33:775-780.

18. Torlakovic E, Torlakovic G, Nguyen PL, Brunning RD, Delabie J. The value of anti-pax-5 immunostaining in routinely fixed and paraffin-embedded sections: a novel pan pre-B and B-cell marker. Am J Surg Pathol 2002;26:1343-1350.

19. Chu PG, Loera S, Huang Q, Weiss LM. Lineage determination of CD20- B-Cell neoplasms: an immunohistochemical study. Am J Clin Pathol 2006;126:534-544.

20. Browne P, Petrosyan K, Hernandez A, Chan JA. The B-cell transcription factors BSAP, Oct-2, and BOB.1 and the pan-Bcell markers CD20, CD22, and CD79a are useful in the differential diagnosis of classic Hodgkin lymphoma. Am J Clin Pathol 2003;120:767-777.

21. McCune RC, Syrbu SI, Vasef MA. Expression profiling of transcription factors Pax-5, Oct-1, Oct-2, BOB.1, and PU.1 in Hodgkin's and non-Hodgkin's lymphomas: a comparative study using high throughput tissue microarrays. Mod Pathol 2006;19:1010-1018.

22. Tiacci E, Pileri S, Orleth A, Pacini R, Tabarrini A, Frenguelli F, Liso A, Diverio D, Lo-Coco F, Falini B. PAX-5 expression in acute leukemias: higher B-lineage specificity than CD79a and selective association with $\mathrm{t}(8 ; 21)$-acute myelogenous leukemia. Cancer Res 2004;64:7399-7404.

23. Valbuena JR, Medeiros LJ, Rassidakis GZ, Hao S, Wu CD, Chen L, Lin P. Expression of B cell-specific activator protein/PAX5 in acute myeloid leukemia with $\mathrm{t}(8 ; 21)$ (q22;q22). Am J Clin Pathol 2006;126:235-240.

24. Kita K, Nakase K, Miwa H, Masuya M, Nishii K, Morita N, Takakura N, Otsuji A, Shirakawa S, Ueda T. Phenotypical characteristics of acute myelocytic leukemia associated with the $t(8 ; 21)(q 22 ; q 22)$ chromosomal abnormality: frequent expression of immature B-cell antigen CD19 together with stem cell antigen CD34. Blood 1992;80:470-477.

25. Valbuena JR, Admirand JH, Gualco G, Medeiros LJ. Myeloid sarcoma involving the breast. Arch Pathol Lab Med 2005;129:32-38.

26. Tamaru J, Tokuhira M, Nittsu N, Nakamura S, Ichinohasama R, Suzuki R, Mori H, Takagi T, Suzuki T, Itami J, Itoyama S, Mikata A. Hodgkin-like anaplastic large cell lymphoma (previously designated in the REAL classification) has same immunophenotypic features to classical Hodgkin lymphoma. Leuk Lymphoma 2007;48:1127-1138.
27. Stein H, Desol G, Pileri SA, Weiss LM, Poppema S, Jaffe ES. Classic Hodgkin lymphoma. In: Swerdlow SH, Campo E, Harris NL, Jaffe ES, Pileri SA, Stein H, Thiele J, Vardiman JW, eds. WHO Classification of Tumours of Haematopoietic and Lymphoid Tissues. 4th ed. Lyon, France: International Agency for Research on Cancer (IARC);2008. 326-329.

\section{Author Affiliations}

Mohamed M. Desouki, MD, PhD*; Ginell R. Post, MD, PhD* Daniel Cherry, MD广; John Lazarchick, MD*

*Department of Pathology \& Laboratory Medicine, Medical University of South Carolina, Charleston, South Carolina, USA

†Department of Pathology, Trident Medical Center, Charleston, South Carolina, USA

tCurrent affiliation: University of Arkansas for Medical Sciences, Little Rock, Arkansas, USA 